\title{
Characterization of Thermally Sprayed Coated GT Components Made of 3D Printing Based Selective Laser Melting Processed Inconel Alloy 718
}

\author{
Mohammed Yunus $(\mathbb{D})$ and Mohammad S. Alsoufi \\ Department of Mechanical Engineering, College of Engineering and Islamic Architecture, Umm Al-Qura University, Makkah, \\ KSA, Saudi Arabia
}

Correspondence should be addressed to Mohammed Yunus; myhasan@uqu.edu.sa

Received 6 April 2021; Revised 4 May 2021; Accepted 24 May 2021; Published 22 June 2021

Academic Editor: Marco Pizzarelli

Copyright (c) 2021 Mohammed Yunus and Mohammad S. Alsoufi. This is an open access article distributed under the Creative Commons Attribution License, which permits unrestricted use, distribution, and reproduction in any medium, provided the original work is properly cited.

\begin{abstract}
Functional requirements like higher strength, resistance, and shielding from chemical reactions, degradation, etc., of the base metal are achieved by modifying their exposed surfaces using TBC (thermal barrier coating). Modified outer surface of components in the GT (gas turbine) improves the performance by the increase of inlet temperature, enhancing longer life and providing many interrelated surfaces to withstand severe working conditions. This work is based on characteristic (mechanical, thermal, and tribology) evaluation of TBC-coated GT components made of Inconel 718 manufactured from traditional and 3-D printingbased selective laser melting (SLM) process and compared. TBCs comprising bond coat and top ceramic oxide coat were deposited by High-Velocity Oxy-Fuel and Atmospheric Plasma Spraying techniques, respectively. Characteristics evaluated by varying coating thickness, standoff distance, substrate preheating, Input torch power, etc., revealed that characteristics of substrates manufactured from SLM methods improved significantly except porosity and average surface roughness. These improvements are essential for embedding sensors, thin films, etc., in TBCs for continuous monitoring of outputs.
\end{abstract}

\section{Introduction}

Gas turbines used in the propulsion of aircraft are characterised by highly structural integrity, low weight, and hightemperature resistant demand higher thermal efficiency, which is extensively dependent on the GT (gas turbine) inlet temperature for extracting higher levels of energy from combustion [1]. To get enhanced thermal efficiency, several studies have been carried out on using newer materials, variation of operative temperature on the properties of high-temperature corrosion, microstructural changes, creep, etc. Various methods like TBCs, air cooling, and thin films have been followed to enhance the high-temperature characteristics of the GT [2] need special attention due to their versatility and multifunction capability.

TBCs are popular with the well-known practices applied on components subjected to high-temperature performance in GT materials (made of IN718, Waspaloy, Hastelloy, etc.) where these materials had a steep fall in tensile strength beyond $600^{\circ} \mathrm{C}$ and a gradual fall between 550 and $600^{\circ} \mathrm{C}$. TBCs were also used with GT materials to handle problems of a higher range of temperatures such as oxidization, thermal cyclic loading, creep, and thermal corrosion. Otherwise, they would affect life and structural integrity [3]. Generally, TBCs are coated by APS or EB-PVD (electron beamphysical vapour deposition) processes. Compressor, combustion chamber (CC), and turbine form a typical GT in which turbine and the $\mathrm{CC}$ are exposed to higher temperatures for along time ensue severe damages and irreparable [4]. TBC consists of different layers of metallic bond and ceramic oxide topcoat on a metallic substrate to offer thermal insulation from an exceedingly high amount of hot gases, which are predominant in the hot region of GT. TBCs also provide various benefits stated above by increasing the durability of the components subjected to high temperatures and stresses. The production of improvised GT enhances life by modifying 
the surface, which thus helps in reducing the maintenance cost. The turbine blades and the combustion liners have to be refurbished with TBCs [5]. TBCs are deposited onto the GT components, which are exposed to high temperatures for attaining low substrate temperatures and allowing high input/inlet temperature as it increases the thermal efficiency. The major life-limiting weakness of TBCs is the oxidation of the $\mathrm{BC}$ [6], and secondly, their liability to be damaged by stress due to higher temperature. The damage mechanisms and ultimate failure of TBCs are yet to be fully understood. Therefore, the TBC material selection is mainly controlled by some of the fundamental prerequisites like melting point, phase transformation, thermal conductivity, thermal expansion, adherences, etc. It is observed that only a handful of materials meet these requirements $[7,8]$.

Plasma spraying can be beneficial on combustion walls/chambers and vanes due to the low production cost. In the past three decades, TBC technology has developed and found applications in various sectors. It is often spotted that TBCs undergo impulsive failure and this often limits their application range. Aircraft engines using TBC systems consist of a thermally insulating ceramic layer of 120 to $250 \mu \mathrm{m}$ thicknesses and a 50 to $120 \mu \mathrm{m}$ metal BC layer between the ceramic oxide TC and the metallic substrate which are generally called duplex TBC often fail due to the mismatching of their coefficients of thermal extension. The $\mathrm{BC}$ is an oxidation-resistant layer used to improve the bond strength and to reduce the effect of thermal expansion mismatch between the ceramic and metallic coats $[9,10]$. At elevated temperatures, $\mathrm{O}_{2}$ in the $\mathrm{CC}$ gets transported from the micro-cracks and voids of TC to the BC. Thus, an oxide film forms on the BC known as TGO (Thermally Grown Oxide) film. This film becomes the reason for the degradation of the TBC system [11].

TGO film depth rises during the oxidation process, which consecutively develops residual stresses at the interface of two coats and leads to delamination of two coats $[12,13]$. As TGO film grows, the TBC stresses increase to have larger stress than the thinner films. In previous studies, the major work dealt with the TBC failures caused by TGO film growth [14]. Investigations on TBC systems $[15,16]$ revealed that $\mathrm{Ni}$ with $\mathrm{Cr}_{2} \mathrm{O}_{2}, \mathrm{Al}_{2} \mathrm{O}_{3}$ as coatings produces $\mathrm{NiO}$ at the interface of ceramic $\mathrm{Al}_{2} \mathrm{O}_{3}$ or YSZ coat with $\mathrm{BC}$ of MCrAlY when exposed at a temperature beyond $1000^{\circ} \mathrm{C}$. The $\mathrm{Ni}$ with $\mathrm{Cr}_{2} \mathrm{O}_{2}, \mathrm{Al}_{2} \mathrm{O}_{3}$ acts as complex oxide causing higher porous within the TGO subfilm forms nucleation spots for crack instigation. These could cause early splitting-up of TC from the $\mathrm{BC}$ where carbon gets deposited, and this carbon moves away in carbon ball form can hit the GT blades [17] causing wear and tear of them. Coatings by plasma spraying on a microscale can be treated as a particle-by-particle build approach. Normally, a splat is formed and this occurs when the particles in their molten state or semimolten state strike the surface of the substrate and get adhered and solidified to form a structure known as "splat." The particles in the plasma stream that do melt are likely to bounce back with a reduction in coating efficiency. It is generally understood that the molten/semimolten particles will be spherical in shape and when impinges onto the substrate at a very high velocity, the particles tend to flatten out into a disk shape; however, a thin sheet of liquid flowing radially turns out to be unstable and collapses to form very fine droplets. This process gets chocked at a stage due to the quick solidification of the droplets. The cooling rate observed at this stage is around $106 \mathrm{~K} / \mathrm{s}$ [18].

At this stage, it is understood that particles tend to lose heat due to conduction and initiate solidification. Heat transfer will also occur due to convection and radiation also. It is also spotted that voids exist in-between the splats as a result of improper bonding that results in the decrease of adhesion due to residual stress and entrapped gases. The factors that influence the structure of the coating include temperature, particle size, average roughness, and velocity. Due to the parameter's variation, there exists a difference in the physical, chemical, mechanical, and even electrical properties also. The ceramic TC is used for the following reasons as they exhibit (a) low thermal conductivity, (b) phase stability, and (c) high melting point. The most widely and commonly used material for providing TC to the substrates under consideration is 6 to 8 wt. \% YSZ. YSZ has low thermal conductivity and exhibits relatively high toughness [19]. Normally, YSZ coatings are preferred since they are corrosion resistant when compared with $\mathrm{CaO}$, and $\mathrm{MgO}$ stabilized Zirconia coatings are used in TBCs $[20,21]$. Spallation effect is also less visible with YSZ coatings [58]. The biggest drawback is limited operating temperature, which makes it difficult in long-range applications. YSZ coating's ability to transport oxygen results in BC oxidation which leads to failure of coatings by spallation is also solved by the TGO film creation. BC role is to provide protection against oxidation and to improve the adhesion with the TC. Normally, NiCrCoAlY alloys are used as BC materials as they provide excellent resistance to oxidation and corrosion. Aluminium acts as a source and reservoir to grow TGO for protection against oxidation [19]. Aluminium is used due to its good adherence and low thermal diffusivity. Chromium safeguards by corrosion and deterioration. In order to avoid diffusion of sulphur into coatings, yttrium can be a choice. TGO film is formed due to BC oxidization. The film is usually formed at the interface of TC and BC.

Alumina is a major oxide produced as a result of the oxidization of NiCrCoAlY. Some of the other oxides include spinel, chromia, silica, and nickel oxide. BC oxidation is known to cause failures in TBCs. Wear resistance and fatigue strength of thermally sprayed ceramic coatings were studied [22]. The results of the research indicate that both the wear resistance and fatigue life of the components increased. The main objective was to investigate the effect of various APS factors of different TBC consisting of $\mathrm{Zr}$ stabilized with magnesia as TC and NiCrCoAlY as BC as well as their properties with those obtained using reference techniques and the optimal conditions. Various techniques associated with the selection of TBC systems would be based on their ability to sustain the harsh, and corrosive atmosphere without phase changes in the ignition compartment. Moreover, emphasized that $\alpha$ of both the coatings and substrate should match each other [23]. The thermal output of YSZ improved by adding $35 \mathrm{wt}$. $\% \mathrm{Al}_{2} \mathrm{O}_{3}$ as it prevents oxygen entry into coatings. APS is widely employed as wear and corrosion-resistant coatings 
TABLE 1: SLM, postprocessing details.

\begin{tabular}{|c|c|c|c|c|c|c|c|c|}
\hline \multicolumn{9}{|c|}{ SLM process } \\
\hline \multirow[b]{2}{*}{$\begin{array}{l}\text { Film } \\
\text { width }\end{array}$} & \multicolumn{4}{|c|}{ Ytterbium $\left(Y_{b}\right)$ fibre laser } & \multicolumn{4}{|c|}{ Postprocessing } \\
\hline & $\begin{array}{c}\text { Beam } \\
\text { diameter }\end{array}$ & $\begin{array}{c}\text { Scanning } \\
\text { speed }\end{array}$ & Capacity & $\begin{array}{l}\text { Hatch } \\
\text { space }\end{array}$ & $\begin{array}{l}\text { Solution } \\
\text { annealing }\end{array}$ & Age hardening & $\begin{array}{l}\text { Furnace } \\
\text { cooling }\end{array}$ & Argon cooling \\
\hline $0.05 \mathrm{~mm}$ & $0.08 \mathrm{~mm}$ & $1500 \mathrm{~m} / \mathrm{s}$ & $0.2 \mathrm{~kW}$ & $0.2 \mathrm{~mm}$ & $950^{\circ}$ for $60 \mathrm{~min}$ & $\begin{array}{l}700^{\circ} \text { for } \\
480 \mathrm{~min}\end{array}$ & $600^{\circ}$ for $60 \mathrm{~min}$ & $\begin{array}{l}600^{\circ} \text { for } \\
480 \mathrm{~min}\end{array}$ \\
\hline
\end{tabular}

TABLE 2: APS and HVOF process parameters.

\begin{tabular}{lcc}
\hline Spraying process & HVOF spraying system & APS spraying technique \\
\hline Type of coat & NiCrAlY & YSZ \\
Spray distance (mm) & $200,225,250,275,300$ & $75,90,110,120,125,140,180$ \\
Transversal speed (mm/s) & 16.67 & - \\
Oxygen pressure (bar)/flow rate (lpm) & $1.1 / 220$ & - \\
Hydrogen pressure(bar)/flow rate (lpm) & $8.6 / 660$ & - \\
Carrier gas/pressure (bar)/flow rate (lpm) & $\mathrm{N}_{2} / 7 / 36$ & - \\
Principal gas flow (Ar) lpm & - & 6.5 \\
Derived gas flow (H2) lpm & - & 4.5 \\
Air pressure (bar)/flow rate (lpm) & $5 / 330$ & - \\
Powder feed rate (kg/hr) & 3.6 & 2.7 \\
Maximum Mach number & 2.4 & - \\
Combustion gas velocity & $850 \mathrm{~m} / \mathrm{sec}$ & - \\
Voltage, V & - & 48 \\
Current, A & - & 500 \\
\hline
\end{tabular}

in aerospace, nuclear energy, textiles, chemicals, plastics, and paper industries and a steady increase found in various applications of TBCs.

High-Velocity Oxy-Fuel (HVOF) employs chemical energy (produced by both thermal and kinetic energies) for coating supersonically driven molten particles of NiCrCoAlY as BC on the surface of Inconel substrates from convergentdivergent nozzle to provide an excellent adhesion property with less porous and thick. APS process employs the gas torch (Make Sulzer Metco) with a copper nozzle operating at high gas flow (Argon gas) and current rates with a jet velocity and the temperature in the range of 600 to $800 \mathrm{~m} / \mathrm{s}$ and 10000 to $18000^{\circ} \mathrm{C}$, respectively. Ceramic and metallic powders are fed into the jet to impinge onto the substrate for forming thick coatings. A struck electric arc between the water-cooled electrodes produces extensive heat and velocity from the plasma gas directed onto substrates by feeding coating powders. CoNiCrAlY deposits impinged on Inconel 718 base metals using APS, supersonic APS, D-gun, HVOF, cold gas dynamic spraying techniques showed enhanced characteristics by dimensional variations in TGO layer, microstructural properties, and chemical compatibilities produced with cold gas dynamic technique [24]. Characteristics of hot corrosion and $\mathrm{CaO}-\mathrm{MgO}-\mathrm{Al}_{2} \mathrm{O}_{3}-\mathrm{SiO}_{2}$ attack demeanours of single and double-layered TBC systems showed double-layered TBC (La2Zr2O7/YSZ) improved properties in terms of variations in TGO layer, microstructures, and chemical as compared to single-layered (YSZ) [25].

Although TBCs enhance GT efficiency by escalating the combustion temperature [26], it is essential to realize the fail- ure mechanisms of TBCs deposited on various substrates. Therefore, in the present research, preparation of TBCs surfaces for applying sputtered thin films required to embed the sensors for measurement in GT. Therefore, the primary aim of the present investigation was to develop thermal barrier coatings on a Direct Metal Laser Sintered IN718 substrate and to compare their characterization with conventional IN718 substrates. Studies with respect to the porosity, bond strength, hardness, adhesion, erosion, etc., have to be carried out to assess tribo, thermo-mechanical performances so that they can be employed for embedding sensors through sputtered thin films for measurements thereafter. In this research work, various test rigs were custom designed and fabricated to facilitate the experimental work [27].

In the present work, the experimental studies focus on APS-enabled coatings on a typical gas turbine engine material of Inconel 718 or IN718. The role of coatings is in achieving higher gas turbine efficiency on conventionally manufactured and SLM-based additive manufactured substrates made of nickel-based superalloy IN718 so that embedded sensors can be accommodated for continuous monitoring.

\section{Materials and Methods}

Flat samples $(30 \mathrm{~mm} \times 50 \mathrm{~mm})$ of two substrates made of INCONEL718 (IN718) prepared to the required dimensions by two methods, namely, conventional manufacturing process (Investment casting) and selective laser melting (SLM) from powdered IN718 metal sintered by the scanning of an 


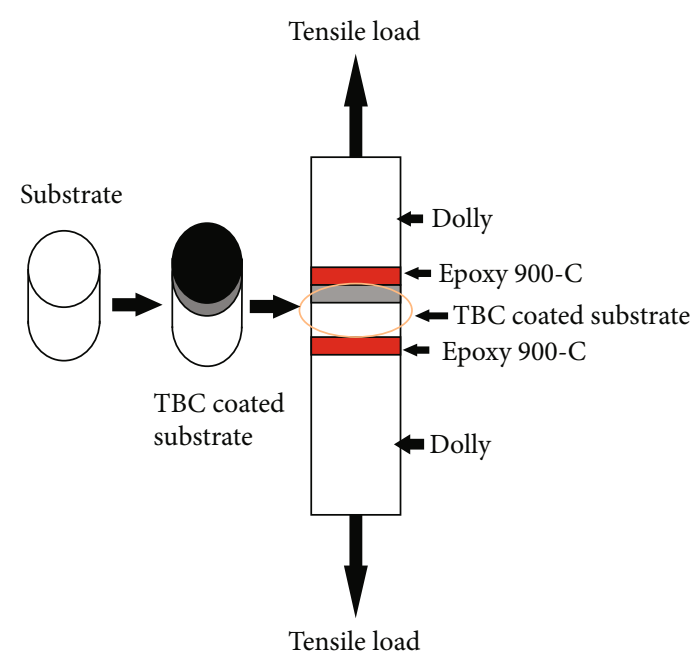

FIGURE 1: Adhesion strength test using ASTM C633 procedure.

Yb-fibre laser at 25 to $50 \mu \mathrm{m}$ layer. SLM method and postprocessing of SLM- IN718 parts carried out using details provided in Table 1. Postprocessing is done by subjecting to series of processes like "solution annealing," "age hardening" followed by cooling within a furnace, and finally, by argon cooling. Whereas conventional IN718 substrates made of Inconel superalloy sheets were cut using EDM wire cutting at optimized cutting parameters. Both substrates were silica sand blasted having 24 mesh size with 24 openings in 1 in $^{2}$ mesh area with maximum size $(690 \mu \mathrm{m})$ sand particle passing through it for generating sufficient surface roughness on the substratum material at pressure (from 2 to 7 bar @ 0.75 bar) for stand-off distance of $75 \mathrm{~mm}$ at $45^{\circ}$ spraying angle to guarantee a fine sticking of coating onto the substrate as it produces moderate indentations on the surface [28]. After blasting, the substrates clean with acetone ultrasonically and degreased by Freon (Chloro-Fluoro-carbon-113) cleaner solvent to produce a very reactive exterior for instant thermal spraying. Substrate surfaces were first deposited NiCrAlY Bond Coat (BC) and 8\% YSZ Topcoat (TC) using HVOF (High-Velocity Oxy-Fuel) and APS (atmospheric Plasma Spraying) processes, respectively, and then cleaned soon after each coating.

A heating scheme consisting of a copper block heater, thermocouple, and temperature controller was used to preheat the test surfaces by holding the specimens in it and heating while their top surface was bond coated by the HVOF process. This leads to the preheating of substrates from 35 to $650^{\circ} \mathrm{C}$ before deposition of bond coats. TBC (Thermal Barrier Coatings) or TCs were deposited via a $3 \mathrm{MB}$ plasma gun (Sulzer Metco made) with $100 \mathrm{~kW}$ power input. Preheating was done to reduce moisture present in the $8 \% \mathrm{YSZ}$ powder. Bond coated (both traditional and SLM Inconel processed) substrates have fixed $\mathrm{BC}$ thickness of $100 \mu \mathrm{m}$ and varying TC thickness from 100 to $500 \mu \mathrm{m}$. The purpose of exceeding the total coat thickness of more than $300 \mu \mathrm{m}$ is to accommodate the embedded sensors in the coatings. The HVOF and APS process factors employed in the experimentation are listed in Table 2.
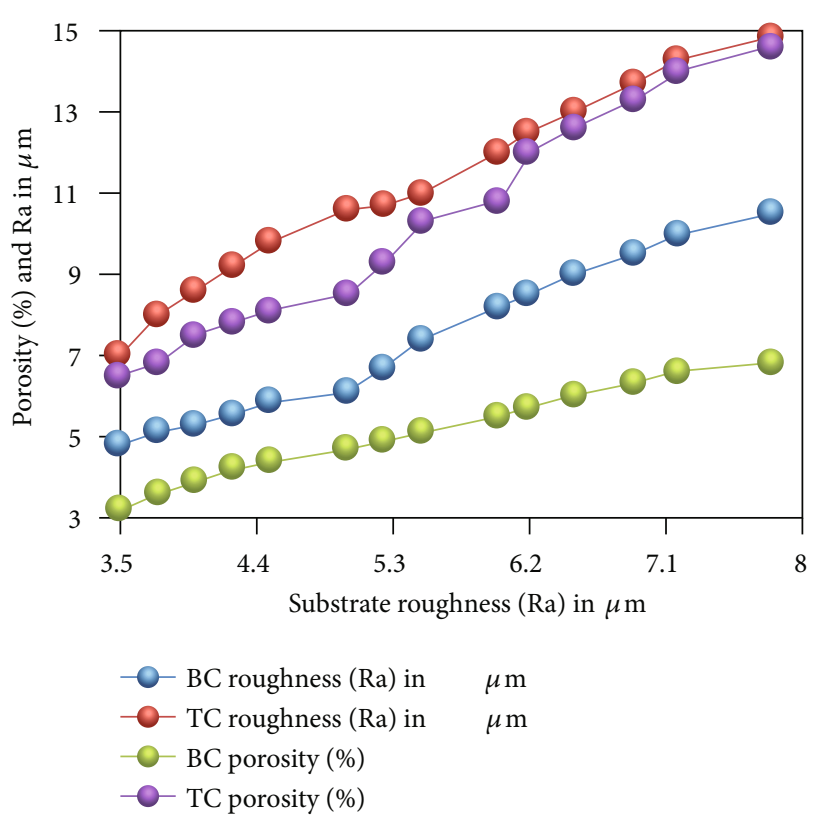

FIgURE 2: \% porosity and $\mathrm{Ra}$ of $\mathrm{BC}$ and TC vs. substrate $\mathrm{Ra}$ of traditional IN718.

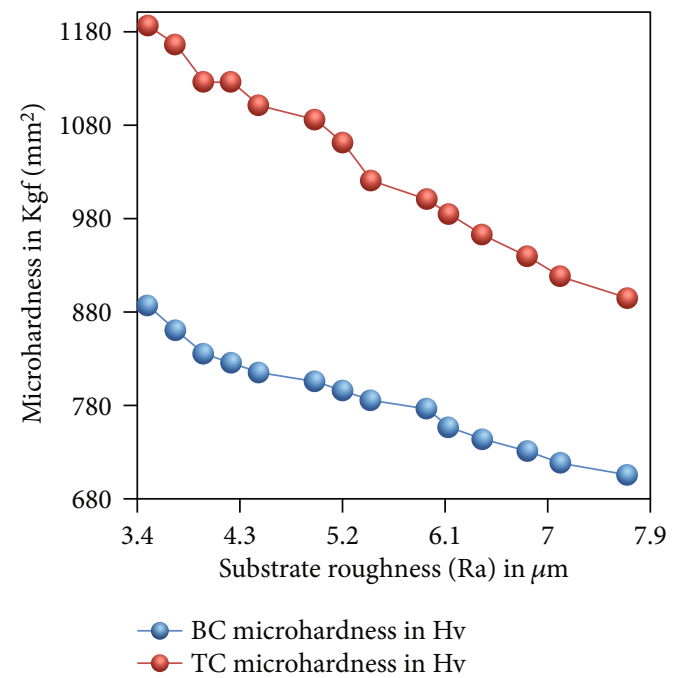

Figure 3: Micro hardness of $\mathrm{BC}$ and TC vs substrate Ra traditional IN718.

Coated samples were polished by holding in PVC tube in acrylic powder and its solution stirred for ten minutes to do cold setting. Using emery paper, from coarse grit size (220) to fine grit size (2000), was applied on the sample crosssection to carry out polishing and then using diamond paste on velvet cloth having a grit size of 5,2 , and 0.5 microns successively.

2.1. Experiments Conducted. Various experiments conducted for evaluating the characterization of TBC on both types of substrates were explained in this portion. The average surface roughness $\left(R_{a}\right)$ of the composite material was measured using a surface roughness measuring device called Taylor Hobson's surface profilometer. The $R_{a}$ of the specimen 
TABLE 3: Various TBC characteristic values for traditional substrates.

\begin{tabular}{|c|c|c|c|c|c|c|}
\hline $\begin{array}{l}\text { Substrate roughness } \\
\left(R_{a}(\mu \mathrm{m})\right)\end{array}$ & $\begin{array}{c}\text { BC roughness } \\
\left(R_{a}(\mu \mathrm{m})\right)\end{array}$ & $\begin{array}{c}\text { TC roughness } \\
\left(R_{a}(\mu \mathrm{m})\right)\end{array}$ & $\begin{array}{c}\text { BC microhardness } \\
(\mathrm{Hv})\end{array}$ & $\begin{array}{c}\text { TC microhardness } \\
(\mathrm{Hv})\end{array}$ & $\begin{array}{c}\text { BC porosity } \\
(\%)\end{array}$ & $\begin{array}{c}\text { TC porosity } \\
(\%)\end{array}$ \\
\hline 3.5 & 4.8 & 7 & 886 & 1185 & 3.2 & 6.5 \\
\hline 3.75 & 5.12 & 8 & 860 & 1165 & 3.6 & 6.8 \\
\hline 4 & 5.3 & 8.6 & 835 & 1148 & 3.9 & 7.5 \\
\hline 4.25 & 5.55 & 9.2 & 825 & 1125 & 4.2 & 7.8 \\
\hline 4.5 & 5.86 & 9.8 & 815 & 1100 & 4.4 & 8.1 \\
\hline 5 & 6.1 & 10.6 & 805 & 1085 & 4.7 & 8.5 \\
\hline 5.25 & 6.7 & 10.7 & 795 & 1060 & 4.9 & 9.3 \\
\hline 5.5 & 7.4 & 11 & 785 & 1020 & 5.1 & 10.3 \\
\hline 6 & 8.2 & 12 & 776 & 1000 & 5.5 & 10.8 \\
\hline 6.2 & 8.5 & 12.5 & 756.5 & 984 & 5.7 & 12 \\
\hline 6.5 & 9 & 13 & 743.8 & 962 & 6 & 12.6 \\
\hline 6.9 & 9.5 & 13.7 & 731 & 939 & 6.3 & 13.3 \\
\hline 7.2 & 10 & 14.3 & 718 & 917 & 6.6 & 14 \\
\hline 7.8 & 10.5 & 14.85 & 705.5 & 894.4 & 6.8 & 14.6 \\
\hline
\end{tabular}

TABLE 4: Various TBC characteristic values for SLM substrates.

\begin{tabular}{|c|c|c|c|c|c|c|}
\hline $\begin{array}{l}\text { Substrate roughness } \\
\left(R_{a}(\mu \mathrm{m})\right)\end{array}$ & $\begin{array}{c}\mathrm{BC} \text { roughness } \\
\left(R_{a}(\mu \mathrm{m})\right)\end{array}$ & $\begin{array}{c}\text { TC roughness } \\
\left(R_{a}(\mu \mathrm{m})\right)\end{array}$ & $\begin{array}{c}\text { BC microhardness } \\
\left(\mathrm{H}_{\mathrm{v}}\right)\end{array}$ & $\begin{array}{c}\text { TC microhardness } \\
\left(\mathrm{H}_{\mathrm{v}}\right)\end{array}$ & $\begin{array}{c}\text { BC porosity } \\
(\%)\end{array}$ & $\begin{array}{c}\text { TC porosity } \\
(\%)\end{array}$ \\
\hline 5 & 6.28 & 9.15 & 860 & 1100 & 3 & 7.5 \\
\hline 5.3 & 6.58 & 9.6 & 844 & 1085 & 3.3 & 8.6 \\
\hline 5.6 & 6.92 & 9.8 & 836 & 1060 & 3.8 & 9.3 \\
\hline 6 & 7.15 & 10.2 & 828 & 1025 & 4 & 10 \\
\hline 6.2 & 7.52 & 10.8 & 820 & 1010 & 4.3 & 11.8 \\
\hline 6.5 & 7.98 & 11.25 & 800 & 990 & 4.6 & 12.8 \\
\hline 6.9 & 8.28 & 11.75 & 788 & 975 & 5 & 13.4 \\
\hline 7.2 & 9.21 & 13 & 770 & 955 & 5.3 & 15 \\
\hline 7.8 & 10.08 & 13.4 & 745 & 915 & 6 & 19.2 \\
\hline
\end{tabular}

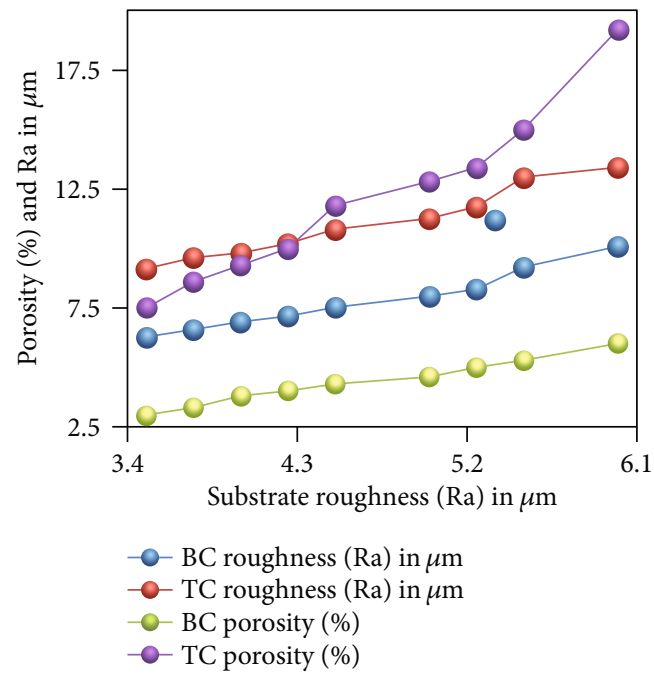

Figure $4: \%$ porosity and $R_{a}$ of BC and TC vs. $R_{a}$ of SLM substrate.

before coating, i.e., on the surface of base metal was measured. Also, after coating with TBC, it was measured.

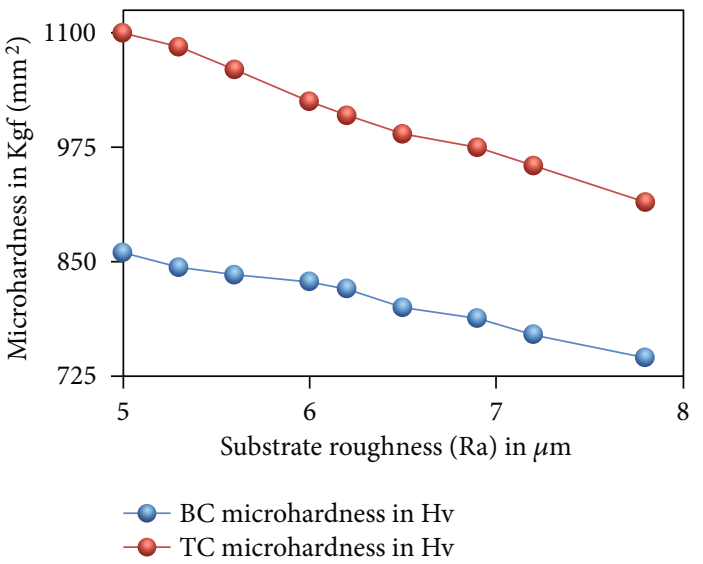

Figure 5: Microhardness of BC and TC vs Ra of SLM substrate.

Microhardness $\left(H_{v}\right)$ of polished TC, BC, and base metal was measured by Vickers microhardness tester controlled by computer employing an OSK 14218-1 (OGAWA SEIKI CO., LTD) tester and applied a load of $300 \mathrm{~g}$ with diamond indenter of the angle of $136^{\circ}$ for 0.2 hour. The hardness of 
TABLE 5: Experimental results of microhardness, \% porosity, and Ra for different SODs.

\begin{tabular}{|c|c|c|c|c|c|c|}
\hline $\begin{array}{l}\text { Stand-off } \\
\text { distance in } \mathrm{mm}\end{array}$ & $\begin{array}{c}\text { Microhardness } H_{v} \text { in } \\
\text { SLM sample }\end{array}$ & $\begin{array}{l}\text { Microhardness } H_{v} \text { in } \\
\text { IN718 sample }\end{array}$ & $\begin{array}{l}\text { \% porosity in } \\
\text { SLM sample }\end{array}$ & $\begin{array}{l}\text { \% porosity in } \\
\text { IN718 sample }\end{array}$ & $\begin{array}{c}R_{a} \text { in SLM } \\
\text { sample }(\mu \mathrm{m})\end{array}$ & $\begin{array}{c}R_{a} \text { in IN718 } \\
\text { samples }(\mu \mathrm{m})\end{array}$ \\
\hline 75 & 1045 & 1110 & 9.5 & 7.8 & 9.9 & 7.7 \\
\hline 90 & 1056 & 1120 & 9.2 & 7.5 & 9.2 & 7.2 \\
\hline 100 & 1080 & 1135 & 8.85 & 7.35 & 9 & 6.7 \\
\hline 110 & 1120 & 1190 & 8.6 & 7 & 8.8 & 6.4 \\
\hline 125 & 1155 & 1205 & 8.15 & 6.8 & 8.5 & 6.2 \\
\hline 140 & 1125 & 1160 & 8.5 & 7.7 & 8.7 & 6.6 \\
\hline 150 & 1070 & 1120 & 8.9 & 8.2 & 8.95 & 6.85 \\
\hline 160 & 1035 & 1085 & 9.45 & 8.9 & 9.4 & 7.6 \\
\hline 180 & 985 & 1035 & 11.5 & 9.8 & 10 & 7.4 \\
\hline
\end{tabular}

the specimen is measured by making an indentation mark on the coated specimen so that a diagonal is formed as a diamond shape indenter is pressed on the surface of the sample. An average value of overall six readings on each specimen was recorded as the data point.

Porosity is assessed by either direct or digital image of coating from the microscope in this study. But the direct way of measuring porosity is evaluated simply as pore volume which is the result of subtracting the total volume of coating with pore from a total volume without pores which is found by a microscope connected with a CCD camera produces an image of the polished surface of coated samples transmitted to image analysis software [29]. The total area arrested by the microscope and area covered by pores are separately measured by the software.

The tension-based adhesive strength of the TC was calculated separately using a unique form of sample holder on a prepared cylindrical dummy sample (diameter $9.5 \mathrm{~mm}$ $\times$ length $25 \mathrm{~mm}$ ) coated. All dummies surfaces were roughened by punching, and each dummy rough surface was then fixed on top of a substrate sample using an "epoxy 900-C" (polymeric adhesive) and subjected to tension after being mounted on the jig (refer to Figure 1). Coated specimens $(\mathrm{Ra}=0.6-1.0 \mu \mathrm{m})$ were placed in a universal-testing machine and pulled having a crosshead speed of $0.02 \mathrm{~mm} / \mathrm{sec}$ until the two parts separated. The coated specimens were prepared by spraying at $650^{\circ} \mathrm{C}$ and room temperature after substrate preheating at $650^{\circ} \mathrm{C}$ could not adhere to the substrate, and so, the adhesion strength could not be measured. Both coatings subjected to tensile test were conducted using at a UTM. The measurement is noted down of load at which the specimen breaks up corresponds to the bond strength of coating [30] performed as per standards of ASTM C633-79. The glued cylinder is assembled in a self-aligning fixture which is mounted on a tensile test machine and pulled in a plane or once rupture occurs, maximum load is recorded (= maximum load/cross-sectional area of the specimen).

The erosion tests were performed at ambient temperature with modified and dark flare spray torch. The coated area $\left(30 \times 30 \mathrm{~mm}^{2}\right)$ surface was subjected to the jet of $\mathrm{Al}_{2} \mathrm{O}_{3}$ particles size varying from $350 \sim 500 \mu \mathrm{m}$ at $20 \mathrm{~m} / \mathrm{s}, 200 \mathrm{~g} / \mathrm{min}$ feed rate, $90^{\circ}$ angle of incidence, $200 \mathrm{~mm}$ stand-off distance, and 20 minutes time of erosion to provide the erosion rate measured for every five minutes in terms of grams of coating eroded per kg of erodent.

\section{Results and Discussion}

Various procedures of coating and trials relating to evaluation of characteristics and their performance of coatings were presented.

3.1. Effect of Substrate's $R_{a}$ on Porosity and Microhardness of Coatings. The $R_{a}$ value of both IN718 and SLM IN718 samples were measured taking an average of $R_{a}$ at 5 different points of sprayed BC and TC surface by surface profilometer shows a great impact on the superior adhesive performance of TBCs [31] onto the substrate. The results of SLM IN718 specimens showed a high amount of average roughness in comparison with the traditional IN718 samples as produced by SLM IN718 samples exhibited very fine and porous structures. This may increase while producing a variety of shapes (comparing Figures 2 and 3). Figure 2 indicates the influence of growing substrate's $R_{a}$ over the roughness of $\mathrm{BC}$ and TC surfaces is seen increasing [32]. It also shows that $R_{a}$ of $\mathrm{BC}$ more than substrate and less than TC due to formation of oxide layers, between metallic BC and TC, facilitates the formation of micromechanical interlocks with their corresponding first coats. Same distribution of $R_{a}$ in SLM IN718 is also seen but higher than IN718 substrates. The $R_{a}$ of SLMIN718 is higher due to its porous structure which allows good adhesion with lesser interlocking of metal with metal BC at microlevel. The TC is already porous in nature which shows higher Ra than both. The comparison of $R_{a}$ values for two substrates is shown in Tables 3 and 4 .

The decaying stage of TBCs through erosion emerges principally on GT components (blades and vanes) mostly when an aircraft GT works in a harsh environment which can be reduced moderately by the reduction of the porosity [33]. In other words, the increased porosity leads to increased thermal shock resistance (TSR) which generally manufacturers prefer. It is also found that microcracked structure in TBCs at times shows higher resistance to erosion wear jointly with higher TSR. The effect of isothermal heating $\left(1100^{\circ} \mathrm{C} / \mathrm{hr}\right)$ on the erosion wear resistance of the TBC system has been presented in terms of porosity where the 


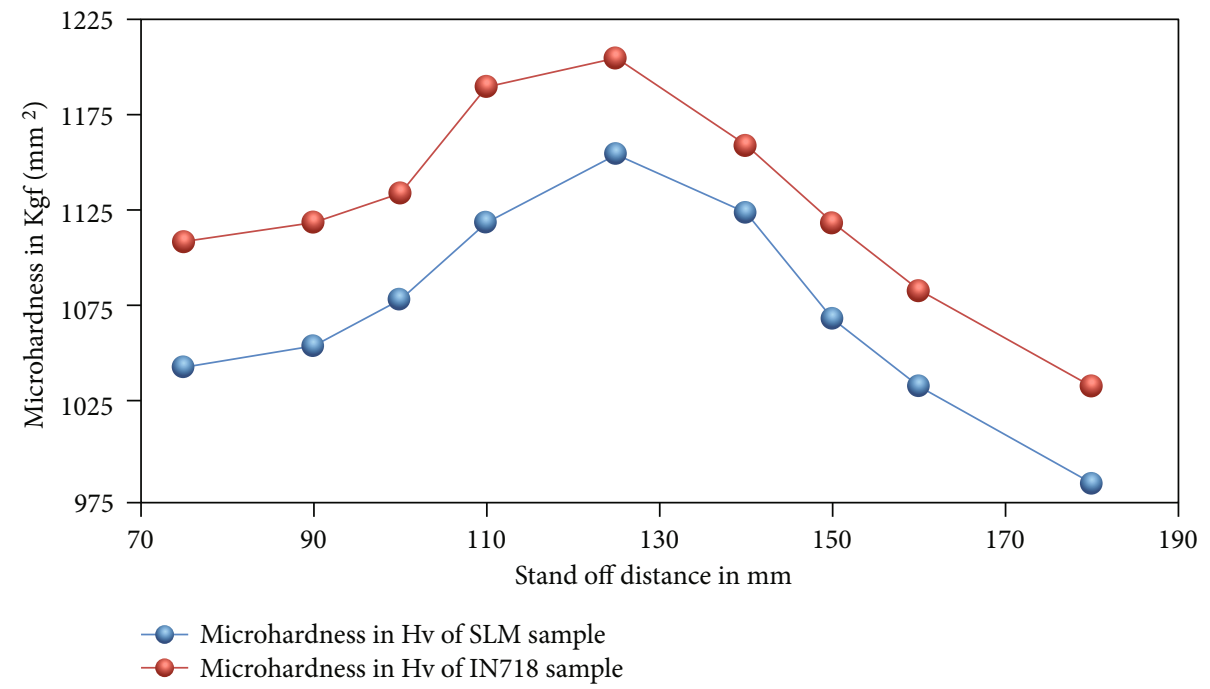

Figure 6: Microhardness of TC vs. SOD.

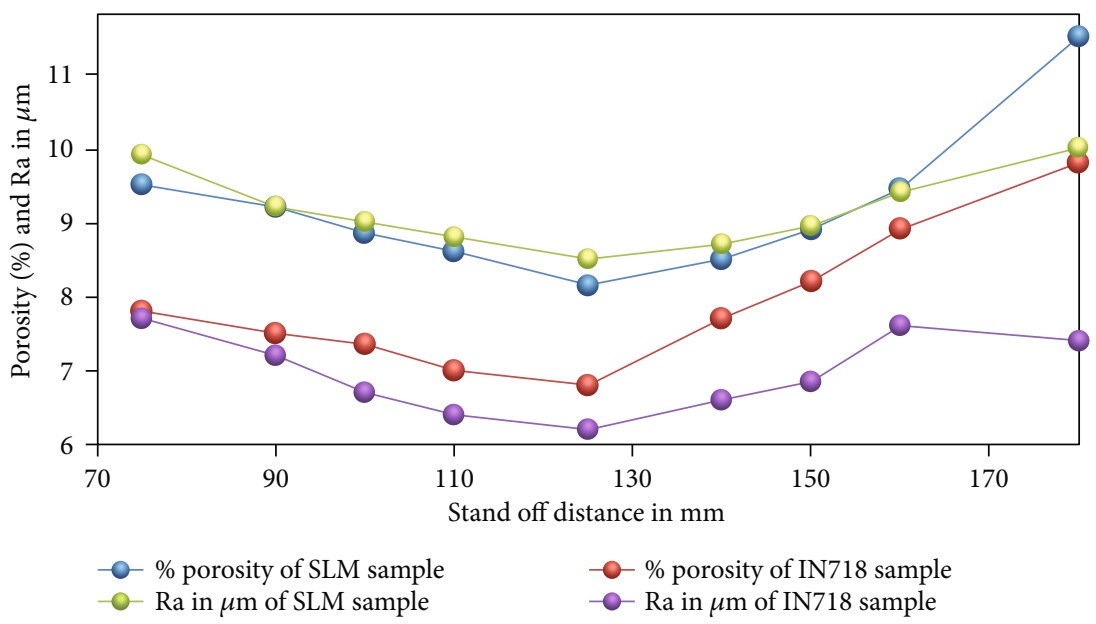

FIgURE 7: \% porosity and $R_{a}$ of TC vs. SOD.

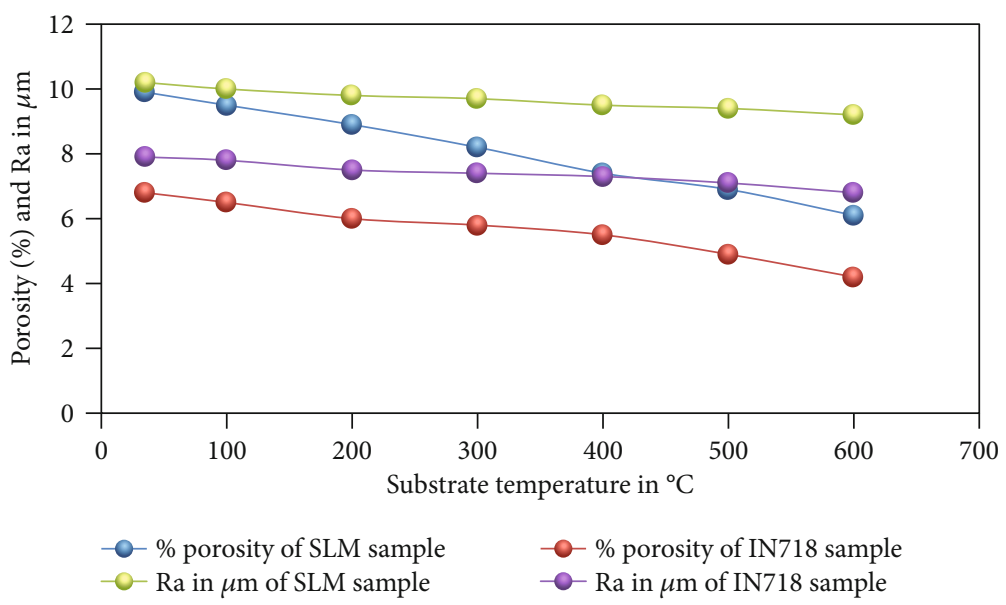

FIGURE 8: \% porosity and $R_{a}$ of TC vs. substrate temperature. 


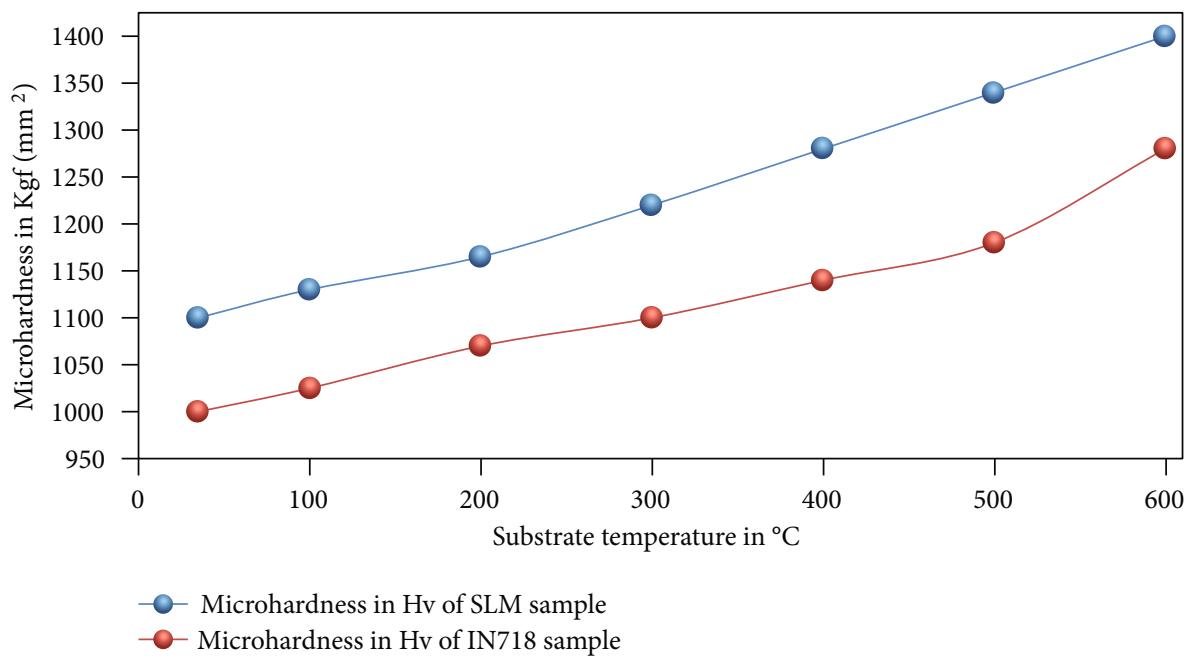

Figure 9: Microhardness of TC versus substrate temperature.

TABLE 6: Results of substrate temperature on the coatings (at SOD of $120 \mathrm{~mm}$ ) for both samples.

\begin{tabular}{lcccccc}
\hline $\begin{array}{l}\text { Substrate } \\
\text { temperature in }{ }^{\circ} \mathrm{C}\end{array}$ & $\begin{array}{c}\text { Microhardness } H_{v} \text { in } \\
\text { SLM sample }\end{array}$ & $\begin{array}{c}\text { Microhardness } H_{v} \text { in } \\
\text { IN718 sample }\end{array}$ & $\begin{array}{c}\text { \% porosity in } \\
\text { SLM sample }\end{array}$ & $\begin{array}{c}\text { \% porosity in } \\
\text { IN718 sample }\end{array}$ & $\begin{array}{c}R_{a} \text { in SLM } \\
\text { sample }(\mu \mathrm{m})\end{array}$ & $\begin{array}{c}R_{a} \text { in IN718 } \\
\text { samples }(\mu \mathrm{m})\end{array}$ \\
\hline 35 & 1100 & 1000 & 9.9 & 6.8 & 10.2 & 7.9 \\
100 & 1130 & 1025 & 9.5 & 6.5 & 7.8 & 70 \\
200 & 1165 & 1070 & 8.9 & 8.2 & 5.8 & 9.8 \\
300 & 1220 & 1100 & 7.4 & 5.5 & 9.7 & 7.5 \\
400 & 1280 & 1140 & 6.9 & 4.9 & 9.4 & 7.3 \\
500 & 1340 & 1280 & 6.1 & 4.2 & 9.2 & 6.8 \\
\hline
\end{tabular}

porosity value varies w.r.t. $R_{a}$, SOD, substrate temperature, and coating thickness [34].

Figure 2 embodies the \% of porosity varying w.r.t $R_{a}$ of a substrate made of traditional IN718 shows BC has less porosity than TC, but the porosity levels increase with the increase in $R_{a}$ of substrate in both cases.

Figure 3 characterizes the \% porosity of BC and TC deposited on SLM IN718 substrates where \% porosity rises in both $\mathrm{BC}$ and TC with the increase of $R_{a}$ of substrate. But the $\%$ porosity in TC deposited on SLM IN718 substrates were more than that of traditional IN718 due to defect free microstructure develop more porous structure for BC, and in turn, this mismatch of interlocking of metals produces more metal oxides between BC and TC. Therefore, TC retains higher $\%$ porosity.

Figure 4 shows the microhardness varying with $R_{a}$ of substrate in traditional and SLM substrates. With the increasing $R_{a}$, the microhardness values were decreased in both BC and TC deposited on both types of base metals. The microhardness values for SLM IN 718 were found to be quite lower than traditional IN718 (refer to Figure 5) in both TC and BC samples and are caused by the porosity in the coating and the development of various phases during and after the TBC coatings [32]. Increasing of $R_{a}$ of substrate rises both $R_{a}$ and porosity of $\mathrm{BC}$ and TC but relatively decreases the hardness value. The higher microhardness decreases the porosity and the $R_{a}$ of coating at the low value of $R_{a}$ of substrate [35].

3.2. Effect of Standoff Distance (SOD) on TBC. The results obtained from experiments revealed that the SOD remained significant parameter affected the TBC's $R_{a}$, microhardness of APS coatings meaningfully (refer to Table 5). Figures 6 and 7 showing the varying of microhardness and \% porosity and $R_{a}$ with respect to SOD. For 75 to $125 \mathrm{~mm}$ of SOD, hardness is found lower and higher porosity and found contrary between 140 and $180 \mathrm{~mm}$ of SOD. The highest hardness is seen at $125 \mathrm{~mm}$ SOD, and lower dense coatings were formed for a high value of SOD. Obviously, it was seen that mostly 8\% YSZ TBC particles scattered at a distance of (between nozzle and substrate) 75-110 and 140-180 mm stayed partially or nonmelted. SOD of $120-125 \mathrm{~mm}$ formed the least porosity or high dense coatings, and the maximum temperature was reached at this optimum distance (115 to $125 \mathrm{~mm}$ ) due to complete melting. Beyond this, the particle temperature was kept on reducing. The optimum condition of SOD in APS process formed results into the maximum $\eta$, the maximum hardness, and low porosity. Less than or more than optimum SOD produced partial or nonmelted coatings with increased average roughness and porosity [15].

Figure 7 depicting the distribution of $R_{a}$ and \% porosity of TC of traditional IN718 and SLM IN718 with respect to 
TABLE 7: TBC characteristics for various coating thicknesses (SOD $125 \mathrm{~mm}$ ).

\begin{tabular}{lcccccc}
\hline $\begin{array}{l}\text { Coating } \\
\text { thickness }(\mu \mathrm{m})\end{array}$ & $\begin{array}{c}\text { Microhardness } H_{v} \text { in } \\
\text { SLM sample }\end{array}$ & $\begin{array}{c}\text { Microhardness } H_{v} \text { in } \\
\text { IN718 sample }\end{array}$ & $\begin{array}{c}\text { \% porosity in } \\
\text { SLM sample }\end{array}$ & $\begin{array}{c}\text { \% porosity in } \\
\text { IN718 sample }\end{array}$ & $\begin{array}{c}R_{a} \text { in SLM } \\
\text { sample }(\mu \mathrm{m})\end{array}$ & $\begin{array}{c}R_{a} \text { in IN718 } \\
\text { samples }(\mu \mathrm{m})\end{array}$ \\
\hline 100 & 1160 & 1200 & 8.1 & 6.6 & 9.2 & 6.5 \\
200 & 1110 & 1175 & 9.5 & 7.5 & 9.8 \\
300 & 1090 & 1130 & 11 & 9 & 11.2 & 7 \\
400 & 1050 & 1090 & 12 & 11.6 & 12.5 \\
500 & 1000 & 1040 & 13 & 13 & 14 & 8.4 \\
600 & 900 & 950 & 14 & 9.2 & 9.6 \\
\hline
\end{tabular}

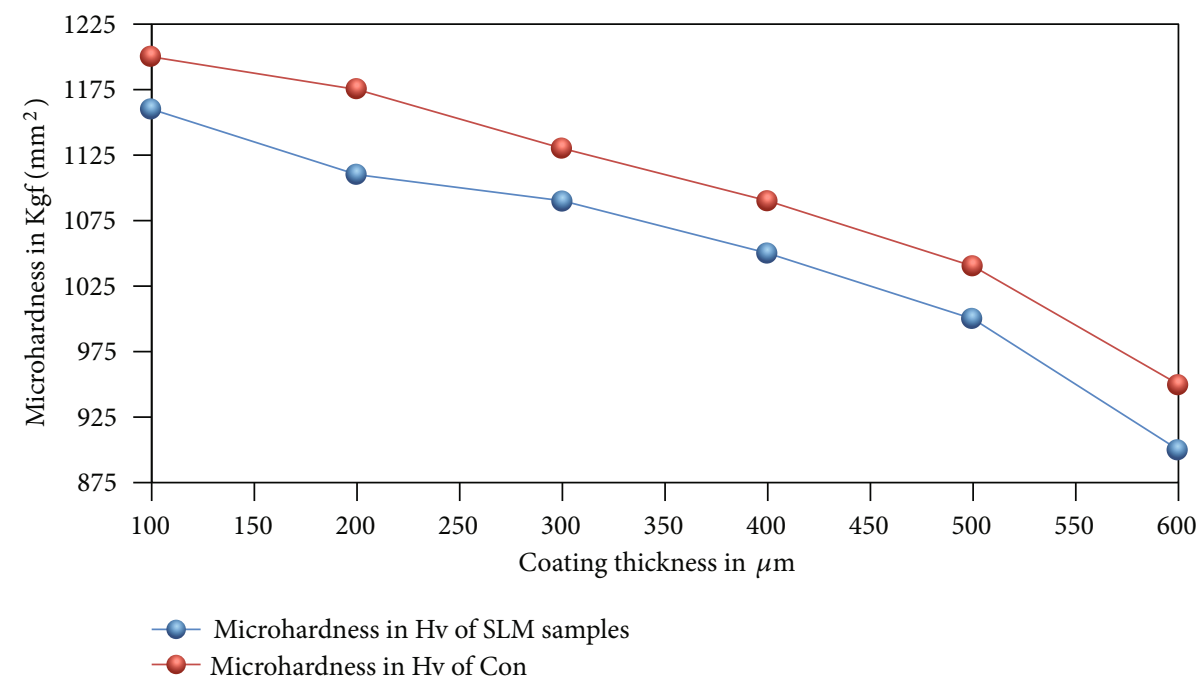

FIgURE 10: Microhardness of TC versus coating thickness.

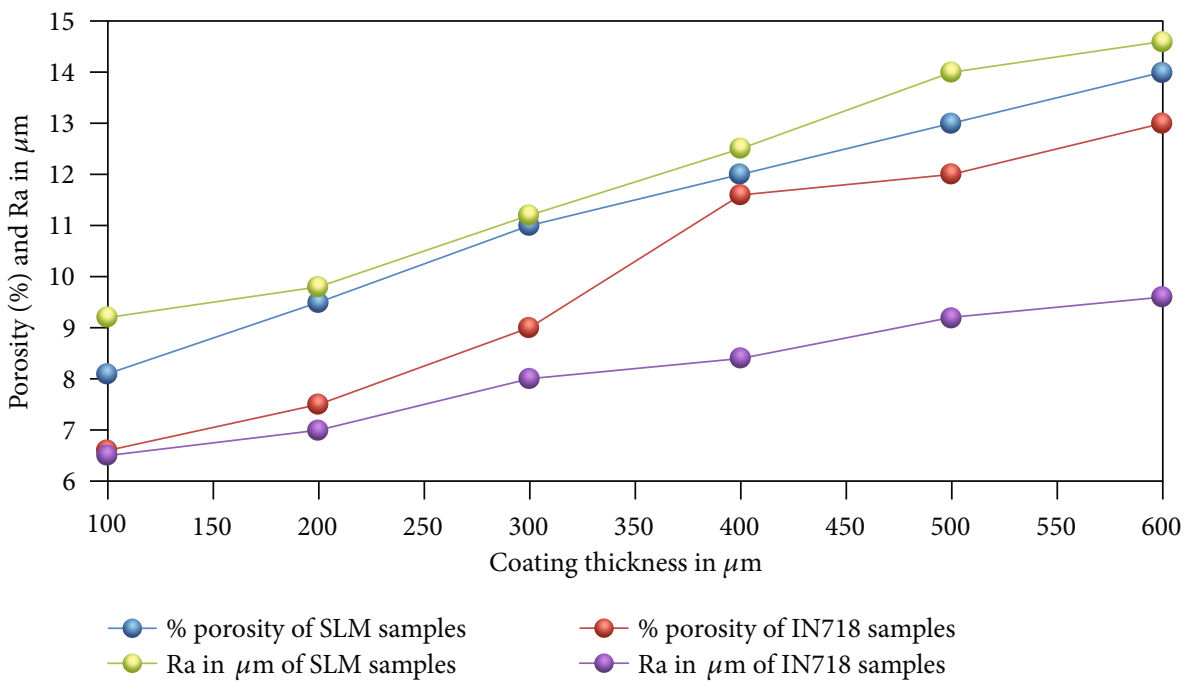

FIGURE 11: \% porosity and Ra of TC versus coating thickness.

SOD shows the coating roughness $R_{a}$ reaches its least value at an optimum SOD range (115 to $125 \mathrm{~mm}$ ) because long SODs are attributed by low element impinging velocity forms numerous visible defects like inappropriately bonded sphere-shaped elements and ample porosity. While short SODs make impinging particles with large momentum in a
TABle 8: AS of NiCrAlY BC using HVOF method.

\begin{tabular}{lc}
\hline Substrate material & AS (MPa) \\
\hline Traditional IN718 & 51 \\
SLM IN718 & 42 \\
\hline
\end{tabular}


TABLE 9: Adhesion strength of TC using APS method.

\begin{tabular}{lcccccccc}
\hline $\begin{array}{l}\text { Power in } \\
\mathrm{kW}\end{array}$ & $\begin{array}{c}\text { AS of SLM } \\
\text { sample }\end{array}$ & $\begin{array}{c}\text { AS of IN718 } \\
\text { sample }\end{array}$ & $\begin{array}{c}\text { Coating thickness } \\
\text { in } \mu \mathrm{m}\end{array}$ & $\begin{array}{c}\text { AS of SLM } \\
\text { sample }\end{array}$ & $\begin{array}{c}\text { AS of IN718 } \\
\text { sample }\end{array}$ & $\begin{array}{c}\text { SOD } \\
\text { AS of SLM } \\
\text { sample }\end{array}$ & $\begin{array}{c}\text { AS of IN718 } \\
\text { sample }\end{array}$ \\
\hline 10 & 18 & 22 & 100 & 28 & 33 & 100 & 28 & 33 \\
12 & 20 & 25 & 150 & 30 & 40 & 125 & 26 & 29 \\
14 & 22 & 27 & 200 & 32 & 41 & 150 & 24 & 23 \\
16 & 27 & 30 & 300 & 22 & 36 & 175 & 20 & 21 \\
18 & 30 & 33 & 400 & 16 & 31 & 200 & 15 & 17 \\
20 & 21 & 27.5 & 500 & 10 & 23 & 225 & 12 & 15 \\
24 & 18 & 23 & 600 & 4 & 13 & & & \\
\hline
\end{tabular}

normal direction to the base metal's surface. Therefore, droplets impinge the base metal at round about $90^{\circ}$ by means of no or at very short velocity parallel to the substrate's surface forms the vertical cracks during cooling. This rises temperature mismatch stress which subsequently cracks to heading towards the thickness.

3.3. Effect of Substrate Temperature. The surface of substrates of both samples was subjected to preheat from ambient $\left(35^{\circ} \mathrm{C}\right)$ to elevated temperatures $\left(600^{\circ} \mathrm{C}\right)$ at steady-state condition before APS coating. The characteristics such as the hardness, \% porosity, and coating roughness $R_{a}$ were obtained with respect to substrate temperature for both samples are plotted in Figures 8 and 9 for studying their influence on the TBCs at optimum SOD of $120 \mathrm{~mm}$ and coating thickness of $100 \mu \mathrm{m}$. Results of TBC coated by APS on a preheated sample revealed minimum substrate and TC porosity and maximum microhardness (refer to Table 6). The TC, BC show at $35^{\circ}$ utmost porosity due to gaps at the interface of coating and base metal, but at high substrate temperature, this gap disappears. Because that substrate temperature modifies the splat structure. With the increase of substrate temperature, a changeover was detected from a droplet of splash to disk droplets. Droplets of splash at high degree are possible to be collapsed by forming secondary droplets. On contrary, disk droplets show small or no fingering pattern because all the droplets are maintained in the central solidifying liquid. Developed liquid droplets on the base metal aid to reduce the bonding of the coat as voids present at the junction of substrate/BC/TC interface resulted from breaking of molten droplets. Only disk molten droplets bond very well to the base metal in improving the adhesion strength of the coating in the form of tensile strength obtained by improved wettability between them. A large number of disk molten droplets attain sluggish solidifying rate of depositing particles instigated by preheating also increased the tensile adhesion strength. AS was also raised particularly when the base metal was at $500^{\circ} \mathrm{C}$ without oxide formation, about 2 to 3 times of AS of a nonpreheated surface. Nevertheless, AS even decreased with preheating when base metal was with oxidation. The same behaviour of preheating worked in a variation of microhardness and $R_{a}$.

In this section, various characteristics such as hardness, roughness, and porosity of substrates were studied with the variation of coating thicknesses are shown in Table 7. The microhardness of the APS used for TC is seen as reducing

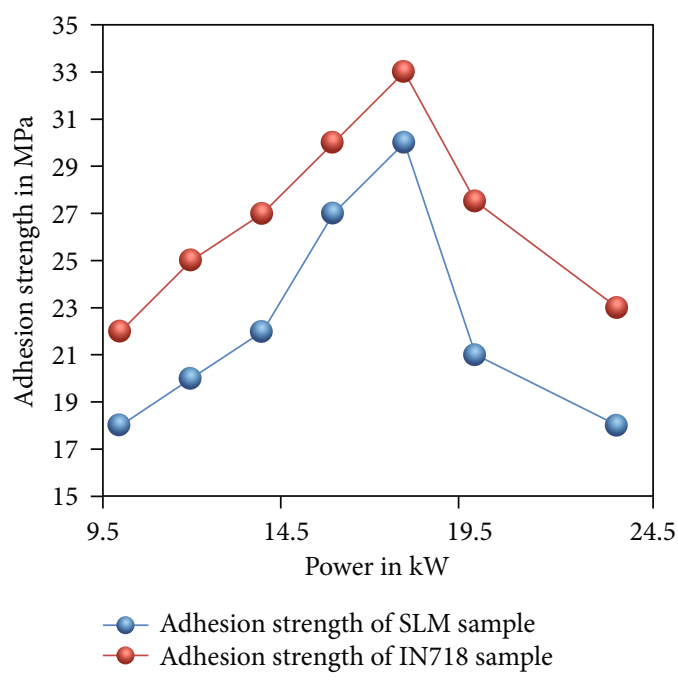

FIGURE 12: Adhesion strength of TC vs. power.

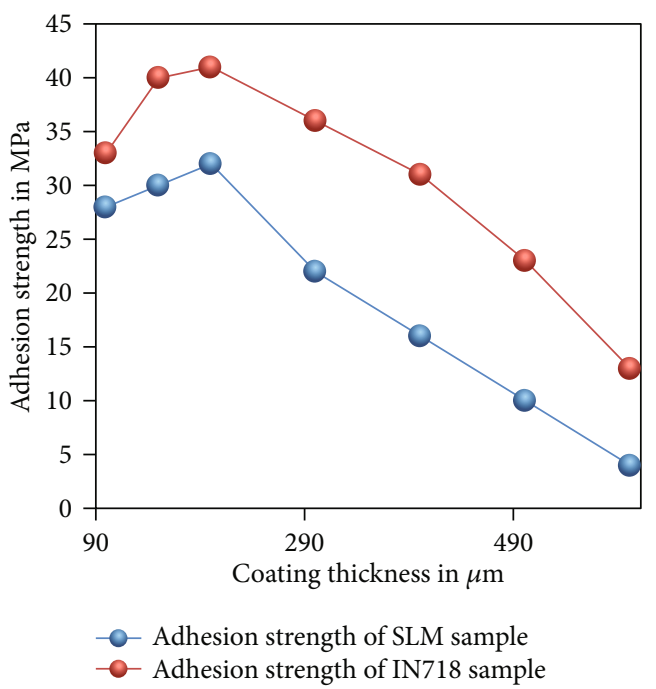

FIGURE 13: Adhesion strength vs. coating thickness at optimum power and SOD.

with the increasing value of coating thickness due to rise in porosity of TBC. Figure 10 depicts the relationship of hardness with varying coating thickness (100 to $600 \mu \mathrm{m}$ ) when TC deposited at SOD of $120 \mathrm{~mm}$ resulted into decreasing hardness with increasing coating thickness. 


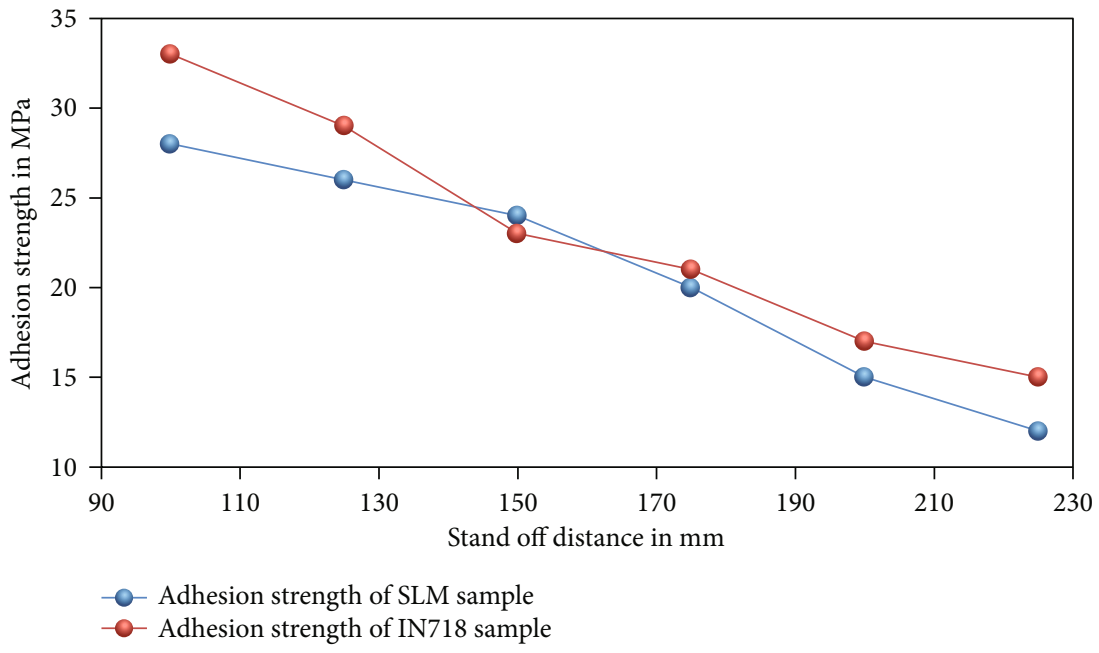

Figure 14: Adhesion of TC vs. SOD.

The changes in porosity level with varying coating thickness are plotted in Figure 11 whereby increasing coating thickness, porosity level also increased due to increasing coating roughness $R_{a}$.

\subsection{Evaluation of Coating-Substrate Adhesion Strength (AS).} In this section, AS of TBCs onto the substrate in respect of $\mathrm{BC}$ is limited to a constant thickness value of $100 \mu \mathrm{m}$ for all both types of substrate surfaces and TC with different coating thicknesses (100 to $600 \mu \mathrm{m})$. The $\mathrm{BC}$ was produced with HVOF technique using an optimum level of parameters as specified in Table 1. Table 8 designates the AS of BC on traditional and SLM substrate materials resulting into constant AS of BC showing the maximum of $51 \mathrm{MPa}$ for traditional IN718 and minimum of $42 \mathrm{MPa}$ for SLM IN718 when it was coated to a thickness of $100 \mu \mathrm{m}$ [16].

AS of TC also called as TBCs were developed using APS process (refer to Table 9) for different coating thicknesses, torch power input to APS process, and SOD as shown in Figures 12-14.

The AS increases with increasing value of torch input power up to $18 \mathrm{~kW}$ and beyond this power decreases (refer to Figure 12) due to increased thermal stresses produced in the coating will remain as residual stresses after developing coatings at increasing power. The residual stresses in the coating decrease the AS of the TBC. The AS of TC shows the maximum value when thickness lies in the range of 150 to $200 \mu \mathrm{m}$ (refer to Figure 13), and beyond this range, as coating thickness increases, AS decreases due to increasing residual stresses in the coating with the increase of thickness.

As it is seen AS reducing with increasing SOD value on both the substrates but SLM IN718 substrates exhibited lower values at all APS process factors (SOD, torch input power, and coating thickness) compared to traditional IN718 when the AS was found out by the coating pull out test based on ASTM C-633 standard. To understand the clear difference between the substrates of traditionally prepared and SLM processed, the maximum AS is compared at $18 \mathrm{~kW}$ of torch power which is about $40 \mathrm{MPa}$ for traditional and
TABLE 10: \% porosity and erosion rate of TBC on two different types of substrates.

\begin{tabular}{lcccc}
\hline No. & $\begin{array}{c}\text { \% porosity for } \\
\text { traditional }\end{array}$ & $\begin{array}{c}\text { Erosion g/kg for } \\
\text { traditional }\end{array}$ & $\begin{array}{c}\text { \% porosity } \\
\text { for SLM }\end{array}$ & $\begin{array}{c}\text { Erosion g/kg } \\
\text { for SLM }\end{array}$ \\
\hline 1 & 6.8 & 5.93 & 8.1 & 10 \\
2 & 7.2 & 7 & 9.1 & 13 \\
3 & 8 & 8 & 9.7 & 14 \\
4 & 8.6 & 10 & 10.5 & 16 \\
5 & 9 & 11 & 12.4 & 18 \\
6 & 9.5 & 12 & 13.6 & 20 \\
7 & 10 & 14 & 14.2 & 21 \\
8 & 11.2 & 16.1 & 16 & 22 \\
9 & 14 & 18 & 20.4 & 24 \\
\hline
\end{tabular}

$30 \mathrm{MPa}$ for SLM substrates when the thickness of coating is $200 \mu \mathrm{m}$ and good AS was achieved for TC (for coating thickness of $150-200 \mu \mathrm{m}$ ) over BC.

Therefore, the present work reveals that increasing the torch input power, the interface bond strength between substrate, $\mathrm{BC}$, and $\mathrm{TC}$ enhances and hence the AS increases. Typically, AS varies as a function of SOD and TIP can be associated with the thermal stage of the impinging particles on to the substrate. Because low amount of power produces the plasma jet stream whose temperature is inadequate to bring all the particles into molten state (partial melting) which only causes only the decrement in the coating strength. Required amount of high plasma temperature is used to complete melting for improving AS of the TBCs.

3.5. Erosion Rate on as Sprayed and Isothermally HeatTreated Coatings. Results of erosion rate (in $\mathrm{gm} / \mathrm{Kg}$ ) of both samples during as sprayed condition as well as heat treated under isothermal condition (refer Table 10). To explore it, initially, the erosion rate for as sprayed without heat treatment is studied with respect to TBC porosity level which shows erosion rate increasing in both samples coated with TBCs with increasing porosity, but higher erosion rate is found in SLM substrates than traditional IN718 ones. 


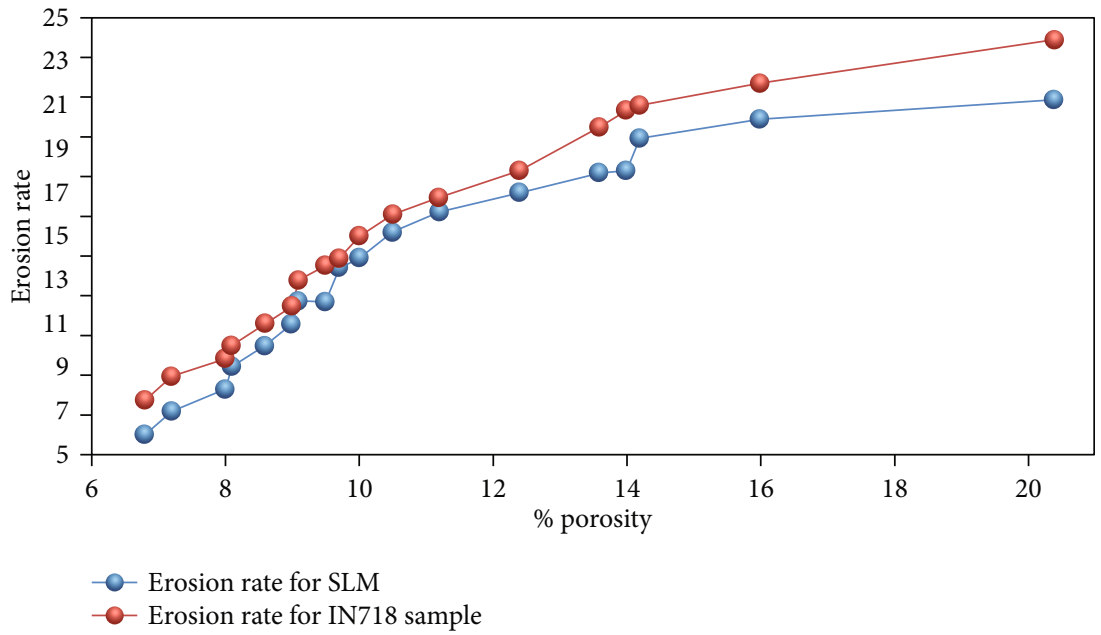

FIGURE 15: Erosion rate of TBC vs. \% porosity. (a) Traditional IN718 and (b) SLM IN718 specimen.

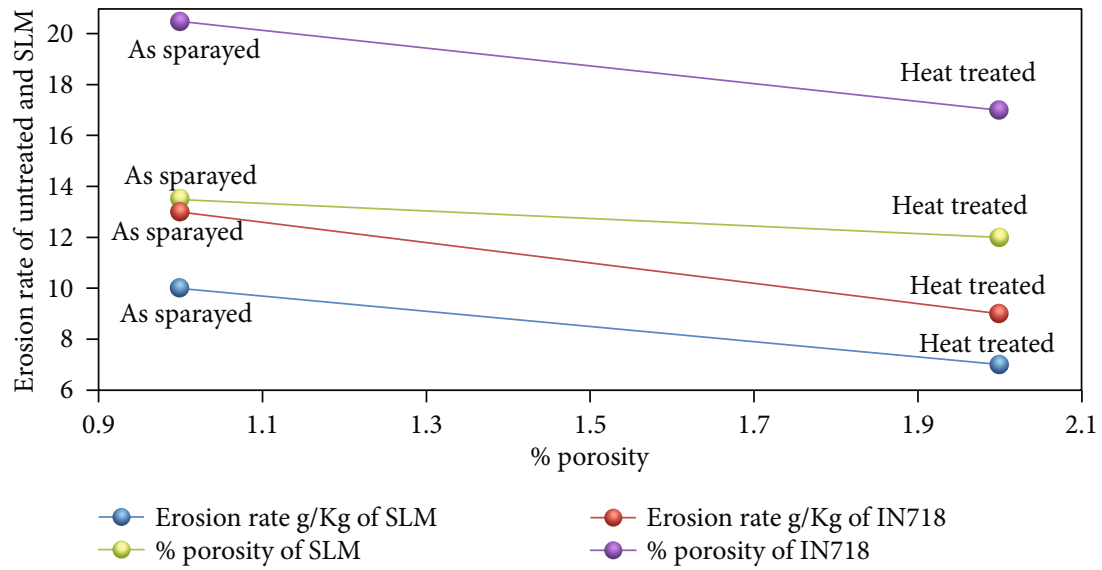

FIgURE 16: Plots of erosion rate vs. \% porosity of TBC for as sprayed and heat-treated samples.

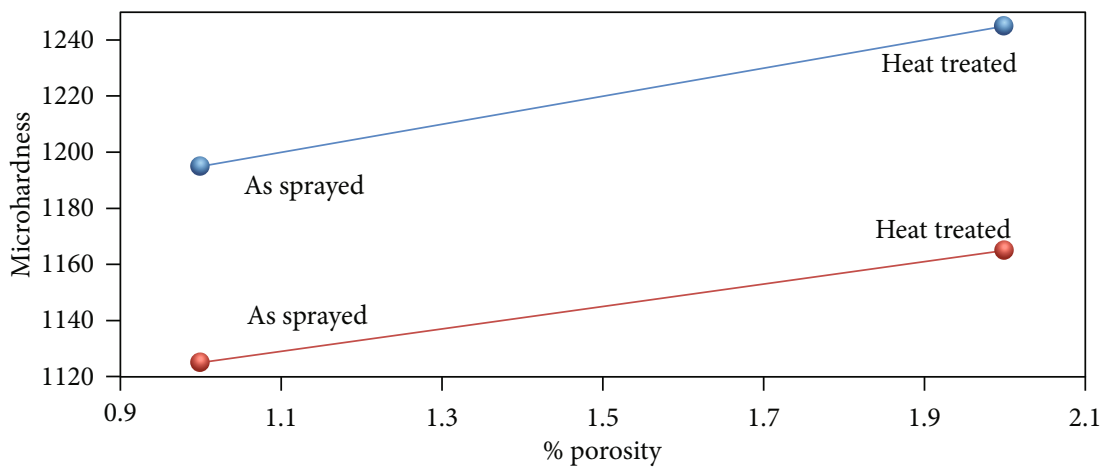

Microhardness in IN718

Microhardness in SLM

Figure 17: Microhardness of TBC for as sprayed and heat-treated samples.

Figure 15 showing the erosion rate in as sprayed and after heat treatment in isothermal condition at $1100^{\circ} \mathrm{C}$ for about 120 minutes was reducing from 18 to $6 \mathrm{~g} / \mathrm{kg}$ for traditional IN 718 and from 24 to $10 \mathrm{~g} / \mathrm{kg}$ of wearing down (abrasive) material for SLM IN718. Figures 16 and 17 showing the results of microhardness increased and porosity decreased for heat-treated samples revealing that heat treatment enhanced their resistance against erosive capacity due to sintering [36]. The results of the erosion rate, porosity level, and microhardness in as sprayed and heat-treated samples of both types were tabulated in Table 10 indicating improved resistance with isothermal heating at $1100^{\circ} \mathrm{C} / \mathrm{hr}$. 


\section{Conclusions}

The $\eta_{\text {thermal }}$ of GT predominantly depends on inlet/input temperature and by its increased value will lead to highvalue efficiency but restricts the working temperatures of GT components, excessive corrosive environment, and changes in microstructure and creep. Selective Laser Melting (SLM) with reference to rapid prototyping GT components used for studying the characterization of samples prepared by sintering of fine powder with high power lasers to compare with conventional IN718 specimens were fabricated by EDM wire cutting. $\mathrm{BC}$ and TC were prepared with $\mathrm{HVOF}$ and APS, respectively. Characterization of TBC is carried out by (1) coatings $\eta$ with respect to various input factors such as SOD and coating powder feed rate; (2) porosity, hardness, surface quality, and erosion are discussed. Experimental results of various characteristics of TBCs on Inconel and SLM Inconel 718 helped to draw the subsequent conclusions:

(i) Surface roughness $\left(R_{a}\right)$ and porosity of TBCs for the deposition of multilayer architecture shown $R_{a}$ value of both IN718 and SLM IN718 samples of as sprayed $\mathrm{BC}$ and TC surface having a great impact on the superior adhesive performance. The influence of substrate $R_{a}$ (before coating) over the $R_{a}$ of $\mathrm{BC}$ and TC surfaces (after coating) in which the $R_{a}$ of both BC and TC surfaces increased as a function of substrate surface such that $R_{a}$ of $\mathrm{TC}>R_{a}$ of $\mathrm{BC}>$ substrate $R_{a}$ and Ra of SLM IN718 substrate $>R_{a}$ of IN718 substrate where higher $R_{a}$ of BC and TC of SLM IN718 > IN718 substrates

(ii) The efficiency of deposition of SLM IN718 samples is found lesser than IN718

(iii) For BC prepared by HVOF spraying process, the $\eta$ is found increased as it could be attributed to high temperatures in the CC by presence of higher quantity of oxygen is increasing with powder feed rate

(iv) For TC APS sprayed, $\eta$ w.r.t. input torch power, standoff distance, and powder supplying rate shown low value in case of SLM IN718 than that of TBCs coated on traditional IN 718 substrates

(v) Erosion rate of heat processed TBCs $>$ as sprayed TBCs. And erosion rate of TBC coated on SLM IN $718<$ TBC on IN718

(vi) TBC on SLM IN718 substrates exhibited good thermal drop verified the use of Selective Laser Manufacturing technique for high-temperature application

The above work may be extended for other types of composite coatings especially for thin coatings. Nanoindentation study above coatings would help in estimating modulus, Poisson ratio, etc., along with hardness for its mechanical strength characterization.

\section{Data Availability}

Data used to support the findings of this study are included within the article.

\section{Conflicts of Interest}

The authors have no conflicts of interest.

\section{Acknowledgments}

The authors would like to thank the Deanship of Scientific Research at Umm Al-Qura University for supporting this work. The authors received financial support for the research and/or for the publication of this article by the Deanship of Scientific Research at Umm Al-Qura University with Grant Code (20UQU073DSR).

\section{References}

[1] R. Eriksson, High-Temperature Degradation of Plasma Sprayed Thermal Barrier Coating Systems, Submitted to Linkoping University, Linköping, Sweden, 2011.

[2] C. G. Levi, "Emerging materials and processes for thermal barrier systems," Current Opinion in Solid State and Materials Science, vol. 8, no. 1, pp. 77-91, 2004.

[3] R. Mévrel, "State of the art on high-temperature corrosionresistant coatings," Materials Science and Engineering: A, vol. 120-121, pp. 13-24, 1989.

[4] M. Belmonte, "Advanced ceramic materials for high temperature applications," Advanced Engineering Materials, vol. 8, no. 8, pp. 693-703, 2006.

[5] A. Lepeshkin, "Investigations of thermal barrier coatings for turbine parts, ceramic coatings - applications in engineering," 2015, https://www.intechopen.com.

[6] A. N. Khan, J. Lu, and H. Liao, "Heat treatment of thermal barrier coatings," Materials Science and Engineering: A, vol. 359, no. 1-2, pp. 129-136, 2003.

[7] C. H. Thistle, "Air plasma sprayed thermal barrier coatings: experiments and finite element analysis, Master's Theses," 2011, Paper 156, https://digitalcommons.uconn.edu/gs_ theses/156.

[8] M. S. Morsi, S. A. El Gwad, M. A. Shoeib, and K. F. Ahmed, "Effect of air plasma sprays parameters on coating performance in zirconia- based thermal barrier coatings," International Journal of Electrochemical Science, vol. 7, p. 2811, 2012.

[9] R. Taylor, Thermal Plasma Processing of Materials - Power Beams and Materials Processing, PBAMP 2002, Ed. A. K. Das et al., Allied Publishers Pvt. Ltd., Mumbai, India, 2002.

[10] H. Singh, T. S. Sidhu, and S. B. S. Kalsi, "Cold spray technology: future of coating deposition processes," Frattura ed Integrità Strutturale, vol. 6, no. 22, pp. 69-84, 2012.

[11] S. Arango, A. Peláez-Vargas, and C. García, "Coating and surface treatments on orthodontic metallic materials," Coatings, vol. 3, no. 1, pp. 1-15, 2013.

[12] A. C. Fox and T. W. Clyne, "Oxygen transport by gas permeation through the zirconia layer in plasma sprayed thermal barrier coatings," Surface and Coatings Technology, vol. 184, no. 2-3, pp. 311-321, 2003.

[13] M. Saremi, A. Afrasiabi, and A. Kobayashi, "Bond coat oxidation and hot corrosion behaviour of plasma sprayed YSZ 
coating on Ni super alloy," Transactions of JWRI, vol. 36, pp. 41-45, 2007.

[14] I. A. Mahmood, W. W. Jameel, and L. A. Khaleel, "Improved oxidation resistance for thermal barrier ceramic coating protect," International Journal of Research in Engineering and Technology, vol. 1, no. 5, pp. 77-86, 2013.

[15] T. J. Steeper, A. J. Rotolico, and J. E. Nerz, "Optimizing plasma sprayed alumina - titania coatings using statistical methods," in Proceedings of the 1993 National Thermal Spray Conference, pp. 7-11, Anaheim, CA, 1993.

[16] Technical article by Oerlikon Metco, An Introduction to Thermal Spray, Thermal Spray Advanced Technology Solutions and Services, 2014.

[17] R. A. Miller and C. E. Lowell, "Failure mechanisms of thermal barrier coatings exposed to elevated temperatures," Thin Solid Films, vol. 95, no. 3, pp. 265-273, 1982.

[18] R. McPherson, "A review of microstructure and properties of plasma sprayed ceramic coatings," Surface and Coatings Technology, vol. 39-40, pp. 173-181, 1989.

[19] N. Curry, Design of Thermal Barrier Coatings, [Ph. D. thesis], no. 3, 2014University West, Sweden, 2014.

[20] X. Q. Cao, R. Vassen, and D. Stoever, "Ceramic materials for thermal barrier coatings," Journal of the European Ceramic Society, vol. 24, no. 1, pp. 1-10, 2004.

[21] W. R. Chen, X. Wu, B. R. Marple, and P. C. Patnaik, “Oxidation and crack nucleation/growth in an air-plasma-sprayed thermal barrier coating with NiCrAlY bond coat," Surface and Coatings Technology, vol. 197, no. 1, pp. 109-115, 2004.

[22] M. Yunus, Investigations on the Properties of Industrial Ceramic Coatings And Characterization, [Ph.D. thesis], Submitted to Anna University, Chennai, 2012.

[23] A. G. Evans, D. R. Clarke, and C. G. Levi, "The influence of oxides on the performance of advanced gas turbines," Journal of the European Ceramic Society, vol. 28, no. 7, pp. 1405-1419, 2008.

[24] A. C. Karaoglanli, Y. Ozgurluk, and K. M. Doleker, "Comparison of microstructure and oxidation behavior of CoNiCrAlY coatings produced by APS, SSAPS, D-gun, HVOF and CGDS techniques," Vacuum, vol. 180, p. 109609, 2020.

[25] A. Ozgurluk, K. M. Doleker, H. Ahlatci, and A. C. Karaoglanli, "Investigation of calcium-magnesium-alumino-silicate (CMAS) resistance and hot corrosion behavior of YSZ and $\mathrm{La}_{2} \mathrm{Zr}_{2} \mathrm{O}_{7} / \mathrm{YSZ}$ thermal barrier coatings (TBCs) produced with CGDS method," Surface and Coatings Technology, vol. 411, article 126969, 2021.

[26] R. C. Reed, The Super Alloys: Fundamentals and Applications, Cambridge University Press, 2006.

[27] W. R. Chen, X. Wu, B. R. Marple, and P. C. Patnaik, "The growth and influence of thermally grown oxide in a thermal barrier coating," Surface and Coatings Technology, vol. 201, no. 3-4, pp. 1074-1079, 2006.

[28] L. Wojnar, Image Analysis Applications in Materials Engineering, CRC Press, Boca Raton, 1999.

[29] C. K. Lin and C. C. Berndt, "Measurement and analysis of adhesion strength for thermally sprayed coatings," Journal of Thermal Spray Technology, vol. 3, no. 1, pp. 75-104, 1994.

[30] M. W. Brumm and H. J. Grabke, "Oxidation behaviour of $\mathrm{NiAl}-\mathrm{II}$. Cavity formation beneath the oxide scale on NiAl of different stoichiometries," Corrosion Science, vol. 34, no. 4, pp. 547-561, 1993.
[31] O. Sarikaya, "Effect of some parameters on microstructure and hardness of alumina coatings prepared by the air plasma spraying process," Surface \& Coatings Technology, vol. 190, no. 2-3, pp. 388-393, 2005.

[32] M. F. J. Koolloos, Behavior of Low Porosity Micro-cracked Thermal Barrier Coatings under Thermal Loading, [Ph.D. thesis], Eindhoven University of Technology, Eindhoven, The Netherlands, 2001.

[33] H. M. Choi, B. S. Kang, W. K. Choi et al., "Effect of the thickness of plasma-sprayed coating on bond strength and thermal fatigue characteristics," Journal of Materials Science, vol. 33, no. 24, pp. 5895-5899, 1998.

[34] K. D. Ambiger and A. Kumar, "Anti-wear behaviour of plasma sprayed alumina \& zirconia coatings on aluminium 7075T6," International Journal of Technical Research and Applications, vol. 2, pp. 235-242, 2014.

[35] E. Celik, I. A. Sengil, and E. Avci, "Effects of some parameters on corrosion behaviour of plasma-sprayed coatings," Surface Coating Technology, vol. 97, no. 1-3, pp. 355-360, 1997.

[36] M. Yunus and M. S. Alsouf, "Post-processing of ceramic oxide and metallic coated surfaces using microwave glazing," High Temperature Material Processes An International Quarterly of High-Technology Plasma Processes, vol. 21, no. 1, pp. 3752, 2017. 